Rev. Adm. Saúde Vol. 17, № 68, Jul. - Set. 2017

http://dx.doi.org/10.23973/ras.68.41

ARTIGO DE REVISÃO

\title{
Auditoria concorrente de enfermagem em prestadores de assistência à saúde: uma revisão integrativa da literatura
}

Nursing Concurrent Audit in Health Care Providers: an integrative review of the literature

\section{Ezequiel Teixeira Andreotti ${ }^{1}$, Maria Augusta da Fonte ${ }^{2}$, Jaqueline Ramires Ipuchima $^{3}$, Cybele Chemale Kessler ${ }^{4}$}

1. Enfermeiro, especialista em auditoria em sistemas de saúde pelo Centro Educacional São Camilo Sul. Doutorando em ciências da saúde pela Universidade Federal de Ciências da Saúde de Porto Alegre (UFCSPA) - Porto Alegre (RS)

2. Enfermeira, mestre em enfermagem pela Universidade de São Paulo (USP). Docente e coordenadora do Núcleo de Metodologia de Pesquisa do Centro Educacional São Camilo - Sul Porto Alegre (RS)

3. Enfermeira, especialista em saúde mental pelo Programa de Residência Multiprofissinal do Hospital de Clínicas de Porto Alegre (HCPA) - Porto Alegre (RS)

4. Enfermeira, mestre em enfermagem pela Universidade do Vale do Rio dos Sinos (UNISINOS). Docente e coordenadora do curso de pós-graduação do Centro Educacional São Camilo - Sul - Porto Alegre (RS)

\section{RESUMO}

A auditoria de enfermagem surge da necessidade de equilíbrio entre os gastos e o aumento da qualidade na assistência aos pacientes por parte dos prestadores de serviços de saúde. O presente estudo teve por objetivo identificar a produção científica brasileira acerca da auditoria concorrente sobre sua importância e suas implicações para melhoria assistencial e de processos nos prestadores de serviço à saúde. Realizou-se uma revisão integrativa com buscas nas bases de dados:

Literatura Latino-Americana e do Caribe em Ciências da Saúde (LILACS), Scientific Electronic Library Online (SCIELO) e Repositório Digital da Universidade Federal do Rio Grande do Sul (UFRGS). Foram selecionados 07 artigos que atenderam aos critérios de inclusão e exclusão. Estes artigos foram analisados através da técnica 
de análise de conteúdo temática. Emergiram duas categorias temáticas: "avaliação assistencial e redução de custos através da auditoria concorrente" e "perspectivas, limites e facilidades no processo de trabalho do enfermeiro auditor". Os estudos analisados, em sua maioria, foram de caráter quantitativo; o ano de maior publicação foi 2013; e o periódico com maior número de publicações foi a Revista Brasileira de Enfermagem. Os estudos mostram a relevância da auditoria concorrente na avaliação da qualidade assistencial e gerencial nas Unidades de Tratamento Intensivo (UTI) e em Centros Cirúrgicos. Além disso, os artigos apontam as transformações ocorridas em prestadores de serviços de saúde que mudaram seu processo de auditoria retrospectiva para auditoria concorrente, enfatizando os limites, facilidades e potencialidades no exercício profissional do enfermeiro auditor. Assuntos como as tendências atuais e futuras também foram mencionadas e revelaram a importância da auditoria concorrente na melhoria da qualidade assistencial, nas mudanças de processos de trabalho e na redução de custos relacionados com o cuidar do paciente. Evidenciou-se com o estudo que, apesar da baixa produção de artigos sobre a temática da auditoria concorrente, este método é visado por estudiosos como uma perspectiva na auditoria de enfermagem por ser um processo completo de avaliação da qualidade da assistência e posterior redução de custos hospitalares.

Palavras-chave: Auditoria de enfermagem. Qualidade da assistência à saúde. Rede prestadora de serviços de saúde

\section{ABSTRACT}

Nursing audit developed from the need to balance expenses and the increasing quality of assistance delivered to patients by Health Care Providers. This study aimed to identify the Brazilian scientific literature about the Concurrent Audit, its relevance and implications for the improvement of processes and assistance by Health Care Providers. An integrative review was carried out in the following databases: the Caribbean and Latin American Literature in Health Sciences (LILACS), Scientific Electronic Library Online (SCIELO), and the Federal University of Rio Grande do Sul Digital Repository (UFRGS). Seven articles that met the inclusion and exclusion criteria were selected and analysed using the thematic content analysis technique. Two thematic categories arose from this analysis: "assistance evaluation and costs reduction through Concurrent Audit"; and "perspectives, limitations and opportunities in the work process of nursing audit". The studies were mainly quantitative, during 2013; Revista Brasileira de Enfermagem was the scientific journal with the highest amount of publications. The studies show the relevance of Concurrent Audit in the evaluation of management and quality of assistance in Intensive Care Units (ICU) and in Surgery Wards. Moreover, they highlight the transformation that happened in Health Care Providers that changed their Retrospective Audit process for the Concurrent Audit, emphasising the limitations and opportunities in the professional performance of nursing audit. Current and future tendencies were also mentioned, and the relevance of Concurrent Audit in the improvement of the quality of assistance, in the work processes, and in costs reduction related to the patient care were shown. With this study, it was verified that despite the low production of articles about the concurrent audit, this method is well 
seen by experts as a perspective in Nursing Audit, due to its completeness in evaluation of quality of assistance and consequent reduction of hospital costs.

Keywords: Nursing audit. Quality of health care. Health services

\section{INTRODUÇÃO}

A necessidade da manutenção da qualidade da assistência traz consigo uma série de desafios e, entre eles, o da redução de custos hospitalares. Dessa forma, surge o trabalho do enfermeiro auditor, que ganha seu espaço através de ações que sigam esta intenção: manter a qualidade com redução de gastos desnecessários.

A auditoria surgiu nos meados dos séculos XV e XVI na Itália, com sua origem a partir da área contábil. Entretanto, no setor saúde, iniciou-se no século $X X$, onde se verificava a qualidade dos serviços prestados aos pacientes, através de análise criteriosa de registros em prontuários, com o foco na redução de custos. A partir disso, no Brasil, a auditoria recebeu maior destaque a partir dos anos 70 , quando passou a ampliar a contratação de enfermeiros para esta área por parte de operadoras e prestadores de serviços de saúde e, em 2001, foi reconhecida pelo Conselho Federal de Enfermagem (COFEN) de acordo com a resolução nำ 266/01 ${ }^{(1)}$.

O enfermeiro auditor vem ganhando destaque por ser uma profissão que, através da sua análise por meio de sua bagagem assistencial e intelectual, visa à melhor forma de assistir o paciente com um gasto adequado.

A auditoria em enfermagem é conceituada como uma análise sistemática da qualidade assistencial prestada ao ser cuidado. É classificada nas seguintes categorias: auditoria retrospectiva, realizada pela avaliação do prontuário; auditoria concorrente, realizada pelo acompanhamento do paciente "in loco"; e, por último, a auditoria prospectiva, realizada através da avaliação prévia dos procedimentos sugeridos pela equipe de saúde ${ }^{(2)}$.

Avaliando a auditoria como método de manutenção da qualidade assistencial, a questão norteadora desta pesquisa é: qual a importância da auditoria concorrente de enfermagem nos prestadores de serviços de saúde para mudanças de processos que resultem em melhor qualidade assistencial e com gastos adequados para a instituição de saúde?

Esta pesquisa apresenta relevância, pois evidencia a essencialidade do enfermeiro auditor na auditoria concorrente nos prestadores, resultando em mudanças de processo na instituição de trabalho, gerando ações que consequentemente melhorem a qualidade assistencial aos pacientes e reduzindo o faturamento indevido. 
Frente ao exposto, decidiu-se por identificar a produção científica brasileira acerca da auditoria concorrente, sobre sua importância e suas implicações para melhoria assistencial e de processos nos prestadores de serviço de saúde.

\section{METODOLOGIA}

\section{Caracterização do estudo}

A pesquisa apresenta-se a partir de uma revisão integrativa da literatura, que pode ser definida como a identificação e análise de estudos importantes para a sociedade e que dão suporte para tomadas de decisões, com o objetivo de aperfeiçoar a práxis do profissional, proporcionando uma síntese de diversas pesquisas publicadas e oportunizando conclusões relacionadas sobre uma determinada área a ser estudada ${ }^{(3)}$.

As etapas para o desenvolvimento da revisão integrativa ${ }^{(4)}$, são:

1. elaboração da questão norteadora;

2. busca na literatura (estabelecimento de critérios de exclusão e de inclusão);

3. coleta de dados;

4. análise dos dados;

5. discussão dos resultados encontrados;

6. apresentação da revisão.

\section{Fontes do estudo e busca na literatura}

Para a revisão bibliográfica, foram efetuadas pesquisas nas seguintes bases de dados: Literatura Latino-Americana e do Caribe em Ciências da Saúde (LILACS), Scientific Eletronic Library Online (SCIELO) e Repositório Digital da Universidade Federal do Rio Grande do Sul (UFRGS).

No estudo foram incluídos artigos relacionados à temática do projeto, artigos com idioma português, acesso online e gratuito do texto completo, em intervalo de tempo de 2007 a 2017. No presente estudo, foram excluídas produções científicas com idioma inglês e espanhol.

Os descritores utilizados na pesquisa foram: "Auditoria de Enfermagem", "Qualidade da Assistência à Saúde" e "Rede Prestadora de Serviços de Saúde".

Os termos foram agrupados em combinações de dois descritores da seguinte forma: auditoria de enfermagem AND qualidade da assistência à saúde; auditoria de 
enfermagem AND rede prestadora de serviços de saúde; qualidade da assistência à saúde AND rede prestadora de serviços de saúde.

Os agrupamentos de descritores são mostrados conforme quadro abaixo:

Quadro 1. Número de artigos encontrados e selecionados na busca de literatura.

\begin{tabular}{|c|c|c|c|}
\hline \multirow[t]{2}{*}{ Descritores } & \multicolumn{3}{|c|}{ Artigos encontrados / selecionados } \\
\hline & LILACS & $\begin{array}{l}\text { REPOSITÓRIO } \\
\text { DIGITAL UFRGS }\end{array}$ & SCIELO \\
\hline $\begin{array}{l}\text { Auditoria de Enfermagem AND } \\
\text { Qualidade da Assistência à Saúde }\end{array}$ & $13 / 3$ & $53 / 1$ & $13 / 6$ \\
\hline $\begin{array}{l}\text { Auditoria de Enfermagem AND } \\
\text { Rede Prestadora de Serviços de } \\
\text { Saúde }\end{array}$ & $3 / 0$ & $10 / 0$ & $0 / 0$ \\
\hline $\begin{array}{l}\text { Qualidade da Assistência à Saúde } \\
\text { AND Rede Prestadora de Serviços } \\
\text { de Saúde }\end{array}$ & $46 / 0$ & $17 / 0$ & $0 / 0$ \\
\hline Sub-total & $62 / 3$ & $80 / 1$ & $13 / 6$ \\
\hline
\end{tabular}

Num total de 155 artigos, após a leitura do título e dos resumos, foram identificadas 10 publicações com potencial referente ao objetivo deste trabalho.

\section{Coleta e análise de dados}

Após a seleção dos 10 artigos com potencial para a realização deste estudo, foi realizada a leitura dos mesmos na íntegra. Posteriormente à leitura, foram excluídos 3 artigos, visto que dois deles se repetiam e um não respondia à questão de pesquisa. Dessa forma, foram incluídas 7 publicações para fazer parte do estudo.

Em seguida, foi elaborado um roteiro de coleta de dados para extrair as informações dos 7 artigos selecionados. O roteiro foi constituído das seguintes informações: número de artigos, título, referência, tema, metodologia, principais resultados, comentários, procedência e descritores.

A análise de dados foi realizada em dois momentos:

Em um primeiro momento, foi realizada a caracterização do perfil das publicações através das informações extraídas do roteiro de coleta de dados. Foram utilizados cálculos de frequência simples e relativa.

Em um segundo momento, ocorreu a leitura detalhada das publicações e houve a análise do conteúdo dos artigos. Os dados foram tratados pela técnica de análise de 
conteúdo temática. Essa técnica é composta pelas seguintes fases: pré-análise, fase de exploração do material e o tratamento dos dados e interpretação ${ }^{(5)}$.

A fase da pré-análise consiste na escolha do material a ser analisado, na retomada da questão de pesquisa e do objetivo inicial da pesquisa, reformulando-os frente ao material coletado. Essa fase foi organizada por meio da leitura flutuante e organização do corpus.

A fase da exploração do material consistiu essencialmente na operação de codificação do mesmo. Primeiramente, realizou-se recorte de cada texto em unidades temáticas. Após, procedeu-se à classificação e à agregação dos dados, escolhendo as categorias empíricas que comandaram a especificação dos temas.

O tratamento dos dados e a interpretação correspondem à fase final, e nela buscouse articular o conteúdo dos artigos selecionados com a revisão da literatura para identificar o conteúdo subjacente ao que foi identificado nas publicações.

\section{Aspectos éticos da pesquisa}

Para a realização deste estudo foi respeitada a autoria dos manuscritos utilizados, conforme a lei ํㅡ 9.610 de 19 de fevereiro de $1988^{(6)}$.

\section{REVISÃO TÉORICA}

\section{Auditoria de enfermagem}

A auditoria iniciou-se no século XII nas empresas, mas teve consolidação no século XVII, em meados da Revolução Industrial, e vem sendo utilizada até os dias de hoje. Como ramificação da auditoria contábil, temos a auditoria de enfermagem que vem mostrando sua relevância nos prestadores de serviços e nas operadoras de planos de saúde, por meio de fiscalização da qualidade assistencial ao paciente através da avaliação de prontuários, acompanhamento do paciente "in loco" e a averiguação da relação do procedimento realizado e os materiais utilizados, para uma cobrança financeira correta ${ }^{(7)}$.

A auditoria de enfermagem vem como um método de redução de gastos com o foco em garantir a qualidade assistencial desde a admissão, durante a internação e após a alta do cliente no hospital (prestador de serviços de saúde).

A realização da auditoria pelo enfermeiro exige diversos deveres, dentre eles atuar com ética, conhecer o contrato entre hospital e operadoras de planos de saúde, estar sempre atualizado, saber sobre os novos produtos no mercado, ser claro e conciso, conhecer detalhadamente o prontuário e a conta do paciente etc. 
Nessa profissão, alguns objetivos são essenciais como assistir o paciente com alta qualidade, efetuar cobrança correta conforme os materiais realmente utilizados, diminuir o desperdício e conter os excessos, entre outros.

Os campos de atuação nos prestadores de saúde pela auditoria de enfermagem, podem ser divididos segundo dois aspectos ${ }^{(8)}$ :

o enfermeiro auditor em ações de educação continuada, orientando a equipe multi e interdisciplinar, que possui permissão para registrar no prontuário, sensibilizando esses profissionais sobre a extrema relevância do preenchimento correto, respondendo às dúvidas frequentes e transmitindo orientações contínuas sobre o processo de auditagem;

a auditoria de Enfermagem no setor de faturamento, onde o enfermeiro realiza a verificação das contas hospitalares, após a alta do cliente, avaliando se o procedimento é compatível entre o prontuário e a conta realizada pelo faturista.

É essencial destacar que a profissão de enfermeiro auditor tem respaldo legal através da resolução 266/2001 do Conselho Federal de Enfermagem e, em relação à sua aplicação, pode ser dividida em: a) auditoria prospectiva: análise dos procedimentos médico-hospitalares antes de sua efetivação; b) auditoria concorrente: é feita no local onde o paciente está internado ou em tratamento ambulatorial; c) auditoria retrospectiva: análise da conta hospitalar após a alta do paciente $^{(9)}$.

Após a definição sobre o que é a auditoria de enfermagem em seu contexto histórico, suas funções, lei que embasa o exercício da profissão e os tipos de auditoria, na categoria seguinte, o estudo focará na auditoria concorrente como tema central da pesquisa.

\section{Auditoria concorrente}

A busca incessante pela qualidade, pelo faturamento correto da conta hospitalar e pela redução de gastos indevidos é a perspectiva atual dos prestadores de serviços de saúde. Nessa linha de pensamento, a auditoria concorrente vem como prespectiva de alcançar essas metas, focando no paciente no momento em que está hospitalizado, com uma análise do enfermeiro auditor "in loco".

A "auditoria concorrente ou operacional é o método investigativo executado pelo enfermeiro auditor enquanto o cliente está hospitalizado ou em atendimento ambulatorial" ${ }^{(10)}$.

Porém, os estudiosos vão além do conceito de auditoria concorrente e exemplificam as quatro formas como pode ser realizada: pela opinião do cliente e seus familiares sobre o cuidado assistencial prestado, por meio de suas percepções sobre o atendimento oferecido; por entrevista do colaborador após assistência, proporcionando um processo reflexivo do funcionário sobre sua práxis de enfermagem; através dos exames realizados pelos clientes se estão relacionados ao conforto associado à necessidade; pela averiguação de se os profissionais estão realizando as atividades propostas para a assistência do paciente ${ }^{(9)}$. 
Outros autores classificam a auditoria concorrente como uma necessidade importante para os prestadores de serviços de saúde. No seu estudo, o método mais utilizado atualmente foi a auditoria retrospectiva (interna), com fiscalização de contas hospitalares com o objetivo de gerar ou reduzir glosas através de informações de prontuários, registros e tratados de enfermagem, com um olhar financeiro e contábil.

Surge então a auditoria concorrente, com avaliação de estruturas, processos e assistência com um olhar inter e multidisciplinar ampliado, com colheita de dados a fim de elaboração técnica, com o objetivo de sinalizar falhas na assistência de enfermagem, revisando sua práxis, sinalizando processos de educação contínua no serviço e objetivando ações corretivas. Também é mencionada a obrigatoriedade de especialização na área para a tomada de decisões embasadas em conhecimento científico atualizado da profissão de enfermeiro auditor ${ }^{(11)}$.

A auditoria concorrente proporciona ao enfermeiro auditor estar no local e no momento em que o cliente está internado, o que favorece o contato com a equipe assistencial. Podem ainda ser observadas e apontadas discordâncias nos registros, ao mesmo tempo em que o auditor pode auxiliar na tirada de dúvidas dos colegas, e acompanhar o paciente "in loco". Além disso, tal método resulta na redução de erros da equipe nos registros de enfermagem e na diminuição do intervalo de tempo entre a alta hospitalar do cliente e o recebimento da fatura pelo convênio. Outros benefícios tornaram-se explícitos, como a emissão dos relatórios como instrumento gerador de capacitações dos profissionais envolvidos com o cuidado, a elaboração de indicadores por meio da auditoria concorrente e que, consequentemente, são acompanhados pela gestão financeira e de enfermagem do hospital, que resulta na melhoria de diversos processos que envolvem toda a equipe multiprofissional e 0 paciente ${ }^{(12)}$.

Nos estudos mencionados acima, pode-se perceber as vantagens que a auditoria operacional proporcionou ao prestador de serviços de saúde, onde foi realizado o estudo, resultando numa melhor compreensão dos profissionais ligados a assistir o paciente, sobre a função do enfermeiro auditor como um profissional que educa e colabora para o gerenciamento do hospital. O enfermeiro auditor não se limita somente à função de análise de prontuários e contas hospitalares, pois seu olhar deve ser holístico, visualizando todos os processos e principalmente o cliente, o cuidado e a maneira como este é dispensado.

\section{Prestador de serviços de saúde}

Os Prestadores de Serviços de Saúde são todas aquelas instituições (hospitais, clínicas, etc), que vendem o seu produto (cuidado em saúde) para a assistência ao cliente.

O hospital é definido como um espaço onde encontram-se diversos serviços, os quais os trabalhadores exercem para assistir o cliente da melhor forma. O prestador vem se aperfeiçoando quotidianamente através de modelos de padronização de qualidade tanto a nível nacional como internacional, como a Joint Commission on Acreditation of Health Care Organizations (JCAHO), a Joint Commission International (JCI), a International Organization for Standardization (ISO) e a 
Organização Nacional de Acreditação (ONA). Tais acreditações servem para a modernização dos hospitais desde o seu modelo arquitetônico até a práxis dos profissionais da saúde ao assistir seu cliente, evitando gastos desnecessários e prestando um serviço de qualidade ${ }^{(13)}$.

A qualidade da assistência é um dos objetivos dos prestadores de serviços de saúde e está associada a uma concepção social e histórica destas instituições. Por este motivo, a dinâmica da qualidade deixa de ser uma expectativa meramente técnica e passa a ser um movimento reflexivo sobre o serviço prestado ao paciente com um olhar holístico por meio de instrumentos como a auditoria, que mantém os padrões estabelecidos pelas certificações e qualificações que fiscalizam alguns modelos de padrões de excelência reconhecidos pela sociedade ${ }^{(8)}$.

Vale destacar que o prestador busca intensamente a melhor forma de proporcionar uma assistência com excelência ao seu cliente. Para que isso ocorra, utiliza-se de um profissional capacitado para esse processo de fiscalização com vistas à melhoria de processos como um todo, que neste caso é o enfermeiro auditor, com seu olhar crítico-reflexivo-generalista, proporcionando mudanças gerenciais e assistenciais nestas instituições. É imprescindível, portanto, que os profissionais da saúde não tenham um olhar sobre a auditoria de enfermagem como uma prática punitiva, mas como uma oportunidade de melhoria para todos os envolvidos com o processo de cuidar nos mais variados setores dos prestadores de saúde.

\section{Apresentação, análise e discussão dos resultados}

Nesta etapa da pesquisa, serão apresentados os resultados obtidos na revisão integrativa com informações referentes à caracterização dos artigos e, em seguida, as categorias temáticas que emergiram da análise dos destes.

O quadro 2 sintetiza as informações sobre procedência, descritores, título, referências e número, conforme citados abaixo.

Quadro 2. Estudo sobre a importância da auditoria concorrente e suas implicações para a melhoria assistencial e de processos nos prestadores de serviço à saúde segundo procedência, descritores, título, referências e número.

\begin{tabular}{|c|c|c|c|c|}
\hline Procedência & Descritores & Título & Referências & № \\
\hline \multirow[t]{2}{*}{ LILACS } & \multirow[t]{2}{*}{$\begin{array}{l}\text { Auditoria de } \\
\text { Enfermagem AND } \\
\text { Qualidade da } \\
\text { Assistência à } \\
\text { Saúde }\end{array}$} & $\begin{array}{l}\text { Qualidade dos } \\
\text { cuidados de } \\
\text { enfermagem em } \\
\text { terapia intensiva: } \\
\text { avaliação por meio } \\
\text { de auditoria } \\
\text { operacional }\end{array}$ & $\begin{array}{l}\text { PADILHA, Elaine Fátima; } \\
\text { MATSUDA, Laura Misue. } \\
\text { Qualidade dos cuidados de } \\
\text { enfermagem em terapia } \\
\text { intensiva: avaliação por } \\
\text { meio de auditoria } \\
\text { operacional. Revista } \\
\text { Brasileira de Enfermagem, } \\
\text { Brasília, v. } 64, \text { n.4, p. 684- } \\
691,2011 .\end{array}$ & 1 \\
\hline & & $\begin{array}{l}\text { Auditoria de } \\
\text { enfermagem em }\end{array}$ & $\begin{array}{l}\text { OLIVEIRA, Driely Reis de; } \\
\text { JACINTO, Silvia Maria; }\end{array}$ & 2 \\
\hline
\end{tabular}




\begin{tabular}{|c|c|c|c|c|}
\hline & & centro cirúrgico & $\begin{array}{l}\text { SIQUEIRA, Cibele Leite. } \\
\text { Auditoria de enfermagem } \\
\text { em centro cirúrgico. } \\
\text { Revista de Administração } \\
\text { em Saúde, São Paulo, v. } \\
\text { 15, n. 61, p. 151-158, 2013. }\end{array}$ & \\
\hline \multirow[t]{4}{*}{ SCIELO } & \multirow[t]{4}{*}{$\begin{array}{l}\text { Auditoria de } \\
\text { Enfermagem AND } \\
\text { Qualidade da } \\
\text { Assistência à } \\
\text { Saúde }\end{array}$} & $\begin{array}{l}\text { Auditoria em } \\
\text { enfermagem: } \\
\text { identificando sua } \\
\text { concepção e } \\
\text { métodos }\end{array}$ & $\begin{array}{l}\text { SCARPARO, Ariane } \\
\text { Fazzolo; FERRAZ, Clarice } \\
\text { Aparecida. Auditoria em } \\
\text { enfermagem: identificando } \\
\text { sua concepção e métodos. } \\
\text { Revista Brasileira de } \\
\text { Enfermagem, Brasília, v. } \\
61, \text { n.3, p. } 302-305,2008 .\end{array}$ & 3 \\
\hline & & $\begin{array}{l}\text { Tendências da } \\
\text { função do } \\
\text { enfermeiro auditor } \\
\text { no mercado em } \\
\text { saúde }\end{array}$ & $\begin{array}{l}\text { SCARPARO, Ariane } \\
\text { Fazzolo et al. Tendências } \\
\text { da função do enfermeiro } \\
\text { auditor no mercado em } \\
\text { saúde. Texto \& Contexto } \\
\text { de Enfermagem, } \\
\text { Florianópolis, v. 19, n. 1, p. } \\
85-92,2010 \text {. }\end{array}$ & 4 \\
\hline & & $\begin{array}{l}\text { Limites e } \\
\text { possibilidades da } \\
\text { auditoria em } \\
\text { enfermagem e seus } \\
\text { aspectos teóricos e } \\
\text { práticos }\end{array}$ & $\begin{array}{l}\text { SILVA, Maria Verônica } \\
\text { Sales. Limites e } \\
\text { possibilidades da auditoria } \\
\text { em enfermagem e seus } \\
\text { aspectos teóricos e } \\
\text { práticos. Revista Brasileira } \\
\text { de Enfermagem, Brasília, v. } \\
65, \text { n. } 3 \text {, p. } 535-538,2012 \text {. }\end{array}$ & 5 \\
\hline & & $\begin{array}{l}\text { Qualidade da } \\
\text { assistência de } \\
\text { enfermagem em } \\
\text { unidade de terapia } \\
\text { intensiva de um } \\
\text { hospital escola }\end{array}$ & $\begin{array}{l}\text { SILVA, Rômulo Botêlho et } \\
\text { al. Qualidade da } \\
\text { assistência de enfermagem } \\
\text { em unidade de terapia } \\
\text { intensiva de um hospital } \\
\text { escola. Revista Gaúcha de } \\
\text { Enfermagem, Porto Alegre, } \\
\text { v. } 34 \text {, n. } 4 \text {, p. 114-120, } \\
2013 \text {. }\end{array}$ & 6 \\
\hline $\begin{array}{l}\text { Repositório } \\
\text { UFRGS }\end{array}$ & $\begin{array}{l}\text { Auditoria de } \\
\text { Enfermagem AND } \\
\text { Qualidade da } \\
\text { Assistência à } \\
\text { Saúde }\end{array}$ & $\begin{array}{l}\text { Implantação da } \\
\text { auditoria } \\
\text { concorrente de } \\
\text { enfermagem: um } \\
\text { relato de } \\
\text { experiência }\end{array}$ & $\begin{array}{l}\text { VIANA, Carla Denise et al. } \\
\text { Implantação da auditoria } \\
\text { concorrente de } \\
\text { enfermagem: um relato de } \\
\text { experiência. Texto \& } \\
\text { Contexto de Enfermagem, } \\
\text { Florianópolis, v. } 25, \text { n. } 1 \text {, p. } \\
\text { 1-7, } 2016 .\end{array}$ & 7 \\
\hline
\end{tabular}

O Quadro 3 resume as informações quanto a número, título, referência, tema, metodologia, principais resultados e comentários.

Quadro 3. Estudo sobre da importância da auditoria concorrente e suas implicações para a melhoria assistencial e de processos nos prestadores de serviço à saúde segundo referências, tema, metodologia, principais resultados e comentários. 


\begin{tabular}{|c|c|c|c|c|c|c|}
\hline № & Título & Referências & Tema & Metodologia & $\begin{array}{l}\text { Principais } \\
\text { resultados }\end{array}$ & Comentários \\
\hline 1 & $\begin{array}{l}\text { Qualidade } \\
\text { dos } \\
\text { cuidados } \\
\text { de } \\
\text { enfermag } \\
\text { em em } \\
\text { terapia } \\
\text { intensiva: } \\
\text { avaliação } \\
\text { por meio } \\
\text { de } \\
\text { auditoria } \\
\text { operacion } \\
\text { al }\end{array}$ & $\begin{array}{l}\text { PADILHA, } \\
\text { Elaine Fátima; } \\
\text { MATSUDA, } \\
\text { Laura Misue. } \\
\text { Qualidade dos } \\
\text { cuidados de } \\
\text { enfermagem } \\
\text { em terapia } \\
\text { intensiva: } \\
\text { avaliação por } \\
\text { meio de } \\
\text { auditoria } \\
\text { operacional. } \\
\text { Revista } \\
\text { Brasileira de } \\
\text { Enfermagem, } \\
\text { Brasília, v. 64, } \\
\text { n.4, p. 684- } \\
691,2011 .\end{array}$ & $\begin{array}{l}\text { Avaliação } \\
\text { dos } \\
\text { cuidados } \\
\text { de } \\
\text { enfermag } \\
\text { em em } \\
\text { UTI para } \\
\text { adultos } \\
\text { através } \\
\text { da } \\
\text { auditoria } \\
\text { operacion } \\
\text { al }\end{array}$ & $\begin{array}{l}\text { Quantitativo - } \\
\text { descritivo, } \\
\text { observacional } \\
\text { e de análise } \\
\text { documental }\end{array}$ & $\begin{array}{l}\text { Com a } \\
\text { auditoria } \\
\text { operacional foi } \\
\text { possível } \\
\text { avaliar a } \\
\text { qualidade dos } \\
\text { cuidados de } \\
\text { enfermagem } \\
\text { em UTI, } \\
\text { contribuindo } \\
\text { assim para } \\
\text { direcionament } \\
\text { o de ações de } \\
\text { melhoria à } \\
\text { equipe } \\
\text { investigada e } \\
\text { outros setores } \\
\text { da instituição. }\end{array}$ & $\begin{array}{l}\text { Foi possível } \\
\text { conhecer a } \\
\text { qualidade dos } \\
\text { cuidados de } \\
\text { enfermagem no } \\
\text { cenário de } \\
\text { estudo através } \\
\text { da auditoria } \\
\text { concorrente. }\end{array}$ \\
\hline 2 & $\begin{array}{l}\text { Auditoria } \\
\text { de } \\
\text { enfermag } \\
\text { em em } \\
\text { centro } \\
\text { cirúrgico }\end{array}$ & $\begin{array}{l}\text { OLIVEIRA, } \\
\text { Driely Reis de; } \\
\text { JACINTO, } \\
\text { Silvia Maria; } \\
\text { SIQUEIRA, } \\
\text { Cibele Leite. } \\
\text { Auditoria de } \\
\text { enfermagem } \\
\text { em centro } \\
\text { cirúrgico. } \\
\text { Revista de } \\
\text { Administração } \\
\text { em Saúde, } \\
\text { São Paulo, v. } \\
\text { 15, n. 61, p. } \\
\text { 151-158, } \\
\text { 2013. }\end{array}$ & $\begin{array}{l}\text { Avaliação } \\
\text { dos } \\
\text { cuidados } \\
\text { de } \\
\text { enfermag } \\
\text { em e } \\
\text { redução } \\
\text { de custos } \\
\text { em centro } \\
\text { cirúrgico. }\end{array}$ & $\begin{array}{l}\text { Qualitativo - } \\
\text { relato de } \\
\text { experiência } \\
\text { com } \\
\text { abordagem } \\
\text { descritiva }\end{array}$ & $\begin{array}{l}\text { Foi } \\
\text { evidenciado } \\
\text { que a falta de } \\
\text { registros, e } \\
\text { anotações da } \\
\text { equipe } \\
\text { multiprofission } \\
\text { al contribui } \\
\text { para uma má } \\
\text { qualidade da } \\
\text { assistência e } \\
\text { dificulta a } \\
\text { cobrança dos } \\
\text { procedimentos } \\
\text { realizados no } \\
\text { centro } \\
\text { cirúrgico. }\end{array}$ & $\begin{array}{l}\text { A auditoria de } \\
\text { enfermagem } \\
\text { contribui para a } \\
\text { melhoria da } \\
\text { qualidade } \\
\text { assistencial, e } \\
\text { principalmente } \\
\text { para apontar os } \\
\text { registros } \\
\text { inadequados } \\
\text { dos } \\
\text { enfermeiros em } \\
\text { sua rotina de } \\
\text { trabalho no } \\
\text { centro cirúrgico. }\end{array}$ \\
\hline 3 & $\begin{array}{l}\text { Auditoria } \\
\text { em } \\
\text { enfermag } \\
\text { em: } \\
\text { identifican } \\
\text { do sua } \\
\text { concepçã } \\
\text { o e } \\
\text { métodos }\end{array}$ & $\begin{array}{l}\text { SCARPARO, } \\
\text { Ariane } \\
\text { Fazzolo; } \\
\text { FERRAZ, } \\
\text { Clarice } \\
\text { Aparecida. } \\
\text { Auditoria em } \\
\text { enfermagem: } \\
\text { identificando } \\
\text { sua } \\
\text { concepção e } \\
\text { métodos. } \\
\text { Revista } \\
\text { Brasileira de } \\
\text { Enfermagem, } \\
\text { Brasília, v. 61, } \\
\text { n.3, p. 302-- } \\
\text { 305, 2008. }\end{array}$ & $\begin{array}{l}\text { Concepçã } \\
\text { o e } \\
\text { métodos } \\
\text { da } \\
\text { auditoria } \\
\text { de } \\
\text { enfermag } \\
\text { em no } \\
\text { cenário } \\
\text { atual e } \\
\text { nos } \\
\text { próximos } \\
\text { cinco } \\
\text { anos. }\end{array}$ & $\begin{array}{l}\text { Quantitativo - } \\
\text { Técnica Delphi }\end{array}$ & $\begin{array}{l}\text { A auditoria de } \\
\text { enfermagem } \\
\text { em Instituições } \\
\text { privadas e } \\
\text { públicas vem } \\
\text { sendo utilizada } \\
\text { como uma } \\
\text { visão contábil } \\
\text { e financeira } \\
\text { com foco na } \\
\text { auditoria } \\
\text { retrospectiva. } \\
\text { Futuramente, a } \\
\text { qualidade da } \\
\text { assistência } \\
\text { estará em } \\
\text { foco, e a } \\
\text { auditoria } \\
\text { concorrente } \\
\text { será } \\
\text { implementada }\end{array}$ & $\begin{array}{l}\text { O estudo } \\
\text { sintetiza que, } \\
\text { no futuro, } \\
\text { haverá } \\
\text { associação da } \\
\text { auditoria } \\
\text { retrospectiva } \\
\text { com a auditoria } \\
\text { concorrente, } \\
\text { com foco não } \\
\text { somente na } \\
\text { redução de } \\
\text { custos, mas } \\
\text { também na } \\
\text { qualidade da } \\
\text { assistência. }\end{array}$ \\
\hline
\end{tabular}




\begin{tabular}{|c|c|c|c|c|c|c|}
\hline & & & & & $\begin{array}{l}\text { como forma de } \\
\text { visão ampliada } \\
\text { e integrada } \\
\text { que contribui } \\
\text { para a melhora } \\
\text { do processo } \\
\text { assistencial. }\end{array}$ & \\
\hline 4 & $\begin{array}{l}\text { Tendência } \\
\text { s da } \\
\text { função do } \\
\text { enfermeir } \\
\text { o auditor } \\
\text { no } \\
\text { mercado } \\
\text { em saúde }\end{array}$ & $\begin{array}{l}\text { SCARPARO, } \\
\text { Ariane } \\
\text { Fazzolo et al. } \\
\text { Tendências da } \\
\text { função do } \\
\text { enfermeiro } \\
\text { auditor no } \\
\text { mercado em } \\
\text { saúde. Texto } \\
\text { \& Contexto de } \\
\text { Enfermagem, } \\
\text { Florianópolis, } \\
\text { v. 19, n. 1, p. } \\
85-92,2010 .\end{array}$ & $\begin{array}{l}\text { Papel do } \\
\text { enfermeir } \\
\text { o auditor } \\
\text { e da } \\
\text { auditoria } \\
\text { em } \\
\text { enfermag } \\
\text { em na } \\
\text { atualidad } \\
\text { e e nos } \\
\text { próximos } \\
\text { cinco } \\
\text { anos. }\end{array}$ & $\begin{array}{l}\text { Quantitativo - } \\
\text { exploratório - } \\
\text { técnica delphi }\end{array}$ & $\begin{array}{l}\text { Atualmente, a } \\
\text { auditoria está } \\
\text { voltada para a } \\
\text { área contábil e } \\
\text { financeira. } \\
\text { Nota-se um } \\
\text { movimento } \\
\text { voltado para a } \\
\text { qualidade, } \\
\text { inclusive por } \\
\text { parte das } \\
\text { operadoras de } \\
\text { saúde. Assim, } \\
\text { um cenário } \\
\text { maior para a } \\
\text { auditoria } \\
\text { concorrente } \\
\text { está sendo } \\
\text { apresentado. }\end{array}$ & $\begin{array}{l}\text { A pesquisa } \\
\text { demonstra que } \\
\text { é possível que } \\
\text { as exigências } \\
\text { do mercado } \\
\text { promovam uma } \\
\text { mudança na } \\
\text { configuração da } \\
\text { auditoria, que, } \\
\text { por sua vez, } \\
\text { será mais } \\
\text { voltada para a } \\
\text { gestão da } \\
\text { qualidade do } \\
\text { cuidado. }\end{array}$ \\
\hline 5 & $\begin{array}{l}\text { Limites e } \\
\text { possibilida } \\
\text { des da } \\
\text { auditoria } \\
\text { em } \\
\text { enfermag } \\
\text { em e seus } \\
\text { aspectos } \\
\text { teóricos e } \\
\text { práticos }\end{array}$ & $\begin{array}{l}\text { SILVA, Maria } \\
\text { Verônica } \\
\text { Sales. Limites } \\
\text { e } \\
\text { possibilidades } \\
\text { da auditoria } \\
\text { em } \\
\text { enfermagem e } \\
\text { seus aspectos } \\
\text { teóricos e } \\
\text { práticos. } \\
\text { Revista } \\
\text { Brasileira de } \\
\text { Enfermagem, } \\
\text { Brasília, v. 65, } \\
\text { n. 3, p. 535- } \\
538,2012 \text {. }\end{array}$ & $\begin{array}{l}\text { Análise } \\
\text { critico- } \\
\text { reflexiva } \\
\text { dos } \\
\text { limites e } \\
\text { possibilid } \\
\text { ades do } \\
\text { trabalho } \\
\text { do } \\
\text { enfermeir } \\
\text { o na } \\
\text { auditoria. }\end{array}$ & $\begin{array}{l}\text { Qualitativo - } \\
\text { análise critico- } \\
\text { reflexiva }\end{array}$ & $\begin{array}{l}\text { O profissional } \\
\text { enfermeiro tem } \\
\text { que garantir a } \\
\text { qualidade da } \\
\text { assistência ao } \\
\text { paciente } \\
\text { fazendo com } \\
\text { que este tenha } \\
\text { confiabilidade } \\
\text { e segurança } \\
\text { em relação ao } \\
\text { profissional. } \\
\text { Também tem } \\
\text { por meta } \\
\text { gerenciar e } \\
\text { subsidiar } \\
\text { decisões da } \\
\text { empresa e } \\
\text { proporcionar } \\
\text { um diálogo } \\
\text { permanente } \\
\text { entre os } \\
\text { prestadores de } \\
\text { serviço. }\end{array}$ & $\begin{array}{l}\text { O texto traz } \\
\text { diversos } \\
\text { desafios para o } \\
\text { desenvolviment } \\
\text { o da auditoria } \\
\text { em } \\
\text { enfermagem: a } \\
\text { descoberta de } \\
\text { uma identidade } \\
\text { profissional; a } \\
\text { integração com } \\
\text { auditores } \\
\text { enfermeiros, o } \\
\text { desenvolviment } \\
\text { o de uma visão } \\
\text { de conjunto da } \\
\text { auditoria em } \\
\text { saúde; o } \\
\text { reconhecimento } \\
\text { dos diferentes } \\
\text { atores que } \\
\text { surgem no } \\
\text { mercado de } \\
\text { auditoria em } \\
\text { saúde; o } \\
\text { aprofundament } \\
\text { o do } \\
\text { conhecimento. }\end{array}$ \\
\hline 6 & $\begin{array}{l}\text { Qualidade } \\
\text { da } \\
\text { assistênci } \\
\text { a de } \\
\text { enfermag } \\
\text { em em }\end{array}$ & $\begin{array}{l}\text { SILVA, } \\
\text { Rômulo } \\
\text { Botêlho et al. } \\
\text { Qualidade da } \\
\text { assistência de } \\
\text { enfermagem }\end{array}$ & $\begin{array}{l}\text { Avaliação } \\
\text { dos } \\
\text { cuidados } \\
\text { de } \\
\text { enfermag } \\
\text { em em }\end{array}$ & $\begin{array}{l}\text { Quantitativo- } \\
\text { transversal } \\
\text { (técnica de } \\
\text { Delphi) }\end{array}$ & $\begin{array}{l}\text { Foi } \\
\text { estabelecido o } \\
\text { diagnóstico } \\
\text { situacional das } \\
\text { práticas de } \\
\text { enfermagem }\end{array}$ & $\begin{array}{l}\text { A pesquisa } \\
\text { atesta a } \\
\text { necessidade de } \\
\text { que a realidade } \\
\text { evidenciada na } \\
\text { UTI seja }\end{array}$ \\
\hline
\end{tabular}




\begin{tabular}{|c|c|c|c|c|c|c|}
\hline & $\begin{array}{l}\text { unidade } \\
\text { de terapia } \\
\text { intensiva } \\
\text { de um } \\
\text { hospital } \\
\text { escola }\end{array}$ & $\begin{array}{l}\text { em unidade } \\
\text { de terapia } \\
\text { intensiva de } \\
\text { um hospital } \\
\text { escola. } \\
\text { Revista } \\
\text { Gaúcha de } \\
\text { Enfermagem, } \\
\text { Porto Alegre, } \\
\text { v. } 34 \text {, n. 4, p. } \\
114-120 \text {, } \\
2013 \text {. }\end{array}$ & $\begin{array}{l}\text { UTI para } \\
\text { adultos } \\
\text { através } \\
\text { da } \\
\text { auditoria } \\
\text { operacion } \\
\text { al. }\end{array}$ & & $\begin{array}{l}\text { no cenário } \\
\text { estudado. } \\
\text { Realidade } \\
\text { considerada } \\
\text { sofrível, de } \\
\text { acordo com o } \\
\text { check-list } \\
\text { utilizado. }\end{array}$ & $\begin{array}{l}\text { trabalhada, } \\
\text { visto que a } \\
\text { realização do } \\
\text { estudo ocorreu } \\
\text { em um hospital } \\
\text { escola, uma } \\
\text { vez que isso } \\
\text { pode acarretar } \\
\text { a reprodução } \\
\text { da realidade do } \\
\text { ambiente do } \\
\text { estudo, o qual } \\
\text { demonstrou } \\
\text { uma } \\
\text { assistência } \\
\text { deficitária. }\end{array}$ \\
\hline 7 & $\begin{array}{l}\text { Implantaç } \\
\text { ão da } \\
\text { auditoria } \\
\text { concorren } \\
\text { te de } \\
\text { enfermag } \\
\text { em: um } \\
\text { relato de } \\
\text { experiênci } \\
\text { a }\end{array}$ & $\begin{array}{l}\text { VIANA, Carla } \\
\text { Denise et al. } \\
\text { Implantação } \\
\text { da auditoria } \\
\text { concorrente } \\
\text { de } \\
\text { enfermagem: } \\
\text { um relato de } \\
\text { experiência. } \\
\text { Texto \& } \\
\text { Contexto de } \\
\text { Enfermagem, } \\
\text { Florianópolis, } \\
\text { v. } 25, \text { n. 1, p. } \\
\text { 1-7, 2016. }\end{array}$ & $\begin{array}{l}\text { Atuação } \\
\text { do } \\
\text { enfermeir } \\
\text { o auditor } \\
\text { - limites, } \\
\text { facilidade } \\
\text { s e } \\
\text { possibilid } \\
\text { ades }\end{array}$ & $\begin{array}{l}\text { Qualitativo - } \\
\text { relato de } \\
\text { experiência }\end{array}$ & $\begin{array}{l}\text { A implantação } \\
\text { da auditoria } \\
\text { concorrente de } \\
\text { enfermagem } \\
\text { demostra a } \\
\text { relevância } \\
\text { desta } \\
\text { metodologia } \\
\text { de trabalho } \\
\text { aplicada ao } \\
\text { contexto } \\
\text { hospitalar. O } \\
\text { trabalho das } \\
\text { enfermeiras, } \\
\text { "in loco" } \\
\text { estreita as } \\
\text { relações com } \\
\text { os demais } \\
\text { profissionais, } \\
\text { auxiliando } \\
\text { inclusive na } \\
\text { visão dos } \\
\text { profissionais } \\
\text { sobre a } \\
\text { auditoria, bem } \\
\text { como } \\
\text { transforma o } \\
\text { trabalho do } \\
\text { enfermeiro } \\
\text { auditor } \\
\text { fazendo com } \\
\text { que este saia } \\
\text { do modelo } \\
\text { tarefeiro e } \\
\text { exaustivo das } \\
\text { revisões de } \\
\text { contas } \\
\text { hospitalares. }\end{array}$ & $\begin{array}{l}\text { O estudo } \\
\text { expressa que o } \\
\text { enfermeiro } \\
\text { auditor deve } \\
\text { buscar a } \\
\text { qualidade da } \\
\text { assistência, } \\
\text { contudo não } \\
\text { deve } \\
\text { desmerecer as } \\
\text { questões } \\
\text { financeiras. } \\
\text { Dessa forma é } \\
\text { necessário que } \\
\text { ele conduza } \\
\text { sua atuação de } \\
\text { modo a } \\
\text { satisfazer estes } \\
\text { dois pontos. }\end{array}$ \\
\hline
\end{tabular}


Os 07 artigos incluídos na pesquisa foram caracterizados da seguinte maneira: o ano de maior produção foi 2013 , com 02 artigos (28,5\%) publicados. Nos demais anos, o número de artigos encontrados se repetiu - 01 artigo (14,3\%) em 2007, 2010, 2011, 2012 e 2016. O quadro 4 mostra esses achados.

Quadro 4. Freqüência e percentual da distribuição dos artigos, segundo ano de publicação.

\begin{tabular}{|l|r|r|}
\hline Ano & Quantidade (n) & Percentual (\%) \\
\hline 2007 & 1 & 14,3 \\
\hline 2010 & 1 & 14,3 \\
\hline 2011 & 1 & 14,3 \\
\hline 2012 & 1 & 14,3 \\
\hline 2013 & 2 & 28,5 \\
\hline 2016 & 1 & 14,3 \\
\hline Total & 7 & 100,0 \\
\hline
\end{tabular}

$\mathrm{Na}$ pesquisa, os periódicos que retornaram da busca foram 04, sendo que o de maior destaque foi a Revista Brasileira de Enfermagem com um total de 03 artigos (42,8\%), seguida pela Revista Texto \& Contexto Enfermagem com 02 artigos (28,5\%). As revistas Administração em Saúde e Revista Gaúcha de Enfermagem apresentaram 01 artigo $(14,3)$ cada uma. Esses resultados são mostrados no quadro 5.

Quadro 5. Frequência e percentual de distribuição dos artigos, segundo periódico de publicação.

\begin{tabular}{|l|r|r|}
\hline Periódico & Quantidade (n) & Percentual (\%) \\
\hline Revista Brasileira de Enfermagem & 03 & 42,8 \\
\hline Revista Texto \& Contexto Enfermagem & 02 & 28,5 \\
\hline Administração em Saúde & 01 & 14,3 \\
\hline Revista Gaúcha de Enfermagem & 01 & 14,3 \\
\hline Total & 07 & 100 \\
\hline
\end{tabular}

Já em relação às metodologias utilizadas nos artigos incluídos na pesquisa, podemos destacar as seguintes: de natureza qualitativa, 03 artigos (42,8\%), e artigos de natureza quantitativa, que compõem o número de 04 artigos $(57,1 \%)$. Os dados podem ser vistos no quadro a seguir. 
Quadro 6. Frequência e percentual da distribuição dos artigos, segundo metodologia utilizada nas publicações.

\begin{tabular}{|l|l|r|r|}
\hline \multicolumn{2}{|l|}{ Metodologia } & Quantidade (n) & \multicolumn{2}{|l|}{$\begin{array}{l}\text { Percentual } \\
\text { (\%) }\end{array}$} \\
\hline Qualitativo & $\begin{array}{l}\text { Analítico } \\
\text { Relato de Experiência }\end{array}$ & 3 & 42,8 \\
\hline Quantitativo & $\begin{array}{l}\text { Exploratório } \\
\text { Descritivo } \\
\text { Transversal }\end{array}$ & 4 & 57,1 \\
\hline Total & & $\mathbf{7}$ & $\mathbf{1 0 0 , 0}$ \\
\hline
\end{tabular}

\section{Conteúdo dos artigos analisados}

Em relação à análise de dados, na segunda etapa da pesquisa, estes são aqui apresentados conforme similaridade de temas. Identificou-se que, dos 07 artigos incluídos na pesquisa, 3 artigos (42,8\%) compõem a categoria temática "avaliação assistencial e redução de custos através da auditoria concorrente" em que foram desenvolvidos os assuntos: avaliação dos cuidados de enfermagem em Unidade de Tratamento Intensivo (UTI), avaliação dos cuidados de enfermagem em Centro Cirúrgico e redução de custos hospitalares. Já a categoria temática "perspectivas, limites e facilidades no processo de trabalho do enfermeiro auditor" conta com 04 artigos $(57,1 \%)$, que abordam os seguintes temas: tendências da auditoria e processo de auditoria nos prestadores de saúde, demonstrados no quadro a seguir:

Quadro 7. Frequência e percentual da distribuição dos artigos, conforme tema abordado.

\begin{tabular}{|l|r|r|}
\hline Temas & Quantidade (n) & Percentual (\%) \\
\hline $\begin{array}{l}\text { Avaliação assistencial e redução de custos através } \\
\text { da auditoria concorrente }\end{array}$ & 3 & 42,8 \\
\hline $\begin{array}{l}\text { Perspectivas, limites e facilidades no processo de } \\
\text { trabalho do enfermeiro auditor }\end{array}$ & 4 & 57,1 \\
\hline Total & $\mathbf{7}$ & $\mathbf{1 0 0}$ \\
\hline
\end{tabular}

\section{Avaliação assistencial e redução de custos através da auditoria concorrente}

Por meio desta categoria, demonstraremos os artigos que relatam a utilização da auditoria concorrente para avaliação da assistência de enfermagem. A auditoria 
concorrente surge, nas publicações, como um meio de avaliação e possível melhoria da assistência para pacientes internados em Unidade de Tratamento Intensivo (UTI) e Centro Cirúrgico, bem como de modo a demonstrar sua efetividade na redução de custos para as operadoras de saúde.

A auditoria concorrente apresenta-se através da verificação do cumprimento das atividades a serem realizadas pelos profissionais por meio de um check-list previamente estabelecido e adaptado para a realidade do ambiente em que foi aplicado $^{(14)}$.

O check-list escolhido conta com 8 itens, quais sejam: higiene e conforto, atividades físicas, segurança física, nutrição e hidratação, oxigenação e ventilação, utilização de equipamentos, eliminações e unidade de terapia intensiva. Cada item possui subitens que contribuem para uma avaliação do cuidado mais abrangente. Como possíveis resultados, têm-se: desejável, adequado, seguro, limítrofe e sofrível.

Neste estudo, os melhores resultados foram nos itens "segurança física" e "utilização dos equipamentos", ambos classificados como "limítrofe". Os demais resultados foram todos considerados "sofrivel".

Outro estudo trouxe o mesmo método de avaliação da assistência ao paciente por meio da auditoria concorrente, tendo como melhor resultado o item "utilização dos equipamentos" e a categoria "desejável" como resultado, seguida por "higiene e conforto" e "segurança física", ambos com resultado "limítrofe". Os demais resultados foram todos considerados "sofrível"(15).

Podemos observar que o item "segurança física" tem resultado "limítrofe" nos dois estudos e que o item "utilização dos equipamentos" também aparece, porém com resultados diferentes em ambos.

Em primeiro lugar, podemos afirmar que este método de avaliação corrobora com as afirmativas deste estudioso, o qual cita que tal método de avaliação pode ser utilizado, pois a auditoria em enfermagem permite que a qualidade do serviço prestado seja observada por meio da avaliação dos prontuários, do acompanhamento do cliente "in loco" e da verificação da conformidade entre a execução das atividades e os elementos que constituem a conta hospitalar cobrada $^{(16)}$.

Mas, o que podemos observar nesses resultados é que ambos os estudos foram realizados em hospitais de ensino e que, dessa forma, a auditoria concorrente tornou possível estabelecer o diagnóstico situacional das práticas de enfermagem, visto que, por serem hospitais-escolas, os potenciais de reprodução em outras instituições de saúde é grande ${ }^{(17)}$.

Também é possível afirmar que a avaliação dos cuidados de enfermagem, por meio da auditoria concorrente, fez com que houvesse o conhecimento da qualidade de boa parte dos cuidados desenvolvidos no serviço participante da pesquisa e que isso não só auxilia no direcionamento das ações de melhoria das práticas da equipe, mas também de outros serviços do hospital ${ }^{(14)}$. 
Assim, observa-se que, nas duas pesquisas, a auditoria concorrente assumiu sua função de identificar as deficiências do serviço da equipe de enfermagem e da assistência recebida pelo paciente, bem como tornou possível que haja a possibilidade de que ocorra algum tipo de treinamento ou orientação para a equipe através do enfermeiro auditor ${ }^{(18)}$.

O foco dos dois artigos é a execução da auditoria concorrente na modalidade de avaliação da qualidade e, então, foi possível observar que nos trabalhos seu desenvolvimento conseguiu cumprir com sua finalidade, trazendo diversas questões que podem ser aprimoradas nas instituições através da educação continuada.

Por sua vez, a educação continuada é uma conseqüência da auditoria concorrente com foco na qualidade, já que essa modalidade de auditoria identifica diversas situações tanto durante a internação quanto através de check-list, prontuários ou questionamentos aos familiares e pacientes ${ }^{(19)}$.

Na publicação deste artigo, o cenário da pesquisa é o Centro Cirúrgico e, através de suas observações, foi possível averiguar que a equipe de enfermagem tem por prioridade assistir o paciente, deixando os registros de enfermagem para outro momento (quando não esquecem de fazê-lo). Dessa forma, o artigo vem mostrar que as anotações de enfermagem são tão importantes quanto o ato de cuidar em si, já que é através dos registros que a terapêutica pode ser mais eficiente ${ }^{(9)}$.

A afirmativa supracitada vai ao encontro do que refere outro pesquisador quando relata que as anotações/registros de enfermagem são ferramentas fundamentais para a auditoria, já que é através delas que pode-se obter a mensuração com precisão da qualidade da assistência prestada pelos serviços de saúde ${ }^{(20)}$.

Assim, no estudo ${ }^{(9)}$ foi possível concluir que, quando há falhas nos registros de enfermagem, a qualidade assistencial deixa a desejar e que a auditoria em enfermagem ainda é pouco conhecida pelos demais enfermeiros.

\section{Perspectivas, limites e facilidades no processo de trabalho do enfermeiro auditor}

Esta categoria conta com 04 artigos que trazem os seguintes temas: "tendências da auditoria" e "processo de auditoria nos prestadores de serviços de saúde".

Na pesquisa ${ }^{(11)}$, ambos se propuseram a avaliar as tendências atuais e futuras dos métodos da auditoria em enfermagem e as opiniões dos trabalhadores da área. Para isso, foi utilizada a técnica de Delphi, que é uma avaliação prospectiva e consensual de tendências. A utilização do método justifica-se pela inexistência de informações suficientes sobre o assunto abordado no âmbito do cenário da pesquisa.

A partir deste estudo, foram avaliadas as características dos profissionais que estão trabalhando na área, tendo como um dos resultados que $84 \%$ dos profissionais não possuem especialização específica na área de auditoria em enfermagem. Com relação à concepção que esses trabalhadores têm sobre auditoria em enfermagem, há a noção de que, atualmente, a ação é totalmente burocrática, de cunho contábil e financeiro, apenas visando à sustentação econômica do hospital. As pesquisadoras 
trazem que, no futuro, a auditoria em enfermagem será mais abrangente fazendo a gestão do cuidado com a finalidade de garantir a qualidade do serviço prestado.

Dessa forma, haverá a execução da sistematização da assistência de enfermagem. Nesta consideração anteriormente mencionada, surge a auditoria concorrente. As autoras dizem que essa tendência de auditoria contempla a análise da estrutura, processo e resultado, considerando um olhar ampliado e integrado, a definição de objetivos e a coleta de dados sobre o processo do cuidado de enfermagem com elaboração de um relatório técnico, tornando, assim, o cuidado muito mais completo, efetivo e com finalidade definida ${ }^{(11)}$.

A utilização da técnica de Delphi teve por fim verificar as tendências futuras e atuais da auditoria, bem como as tendências da função do enfermeiro auditor no mercado de trabalho. Com essa pesquisa, chegaram aos seguintes resultados: a auditoria concorrente, por ser uma análise estruturada com processos e resultados, é a aposta para o futuro e vem agregada à auditoria retrospectiva. Assim podemos observar que, futuramente, a preocupação maior da auditoria, além da redução de custos, será com foco na qualidade da assistência. A pesquisa também nos traz dados referentes ao entendimento que os enfermeiros auditores têm sobre a finalidade da auditoria, chegando à conclusão de que não há consenso, dadas as várias possibilidades existentes no campo. Assim, a autora conclui que a avaliação da qualidade da assistência tem maior resposta quando realizada através da auditoria concorrente, que esta é a aposta para o futuro e que sem essa avaliação não há como reduzir custos, uma vez que a qualidade assistencial satisfatória acarreta menor tempo de internação, o que, consequentemente, gera menos gastos para a rede prestadora de serviços de saúde ${ }^{(21)}$.

Com os dois estudos supramencionados, pode-se observar que a auditoria em enfermagem é um item fundamental para que a qualidade na assistência seja verificada. Este fato corrobora com esta pesquisa ${ }^{(2)}$, quando os autores afirmam que a auditoria em enfermagem é a referência para a avaliação custo-benefício como um instrumento de controle de qualidade da assistência prestada. Os mesmos complementam o pensamento afirmando que a auditoria em enfermagem consagra a excelência do atendimento propriamente dito, proporcionando a melhora do gerenciamento do cuidado.

Na pesquisa realizada neste estudo ora apresentado, foi possível encontrar artigos com análise crítico-reflexiva referente à auditoria em enfermagem e com foco em seus limites e possibilidades e aspectos teóricos e práticos. É o que afirmam estudiosos $^{(17)}$ ao refletirem sobre o papel do enfermeiro auditor e ao afirmarem que a ele compete a garantia da qualidade da assistência prestada ao paciente, fornecendo confiabilidade e segurança nas relações, viabilizando economicamente a empresa, efetuando o levantamento de custos assistenciais com o intuito de determinar metas gerenciais, fazendo a provisão e a adequação dos materiais utilizados, conferindo a correta utilização/cobrança dos recursos técnicos disponíveis, educando a operadora e os prestadores de serviço, proporcionando um espaço de permanente diálogo entre prestador-empresa-usuário. A análise ressalta ainda que é importante que o trabalho do enfermeiro auditor não se limite em ser apenas de análise de prontuários, mas que ele desenvolva habilidades técnicas, políticas e cientificas sobre o trabalho nessa área. Os autores chegam à conclusão de que há muitos desafios na auditoria em enfermagem, dentre eles a necessidade da descoberta de uma identidade profissional, a integração com demais auditores, a 
articulação interdisciplinar, o aprofundamento do conhecimento e a busca pela essência da auditoria.

A auditoria em enfermagem está em crescente expansão e a atuação do enfermeiro auditor tem papel fundamental quando o propósito é otimizar os custos, evitar desperdícios e garantir a realização adequada de todos os procedimentos. A auditoria traz benefícios para a instituição e para o paciente, visto que tem por finalidade a maior qualidade da assistência prestada e a satisfação do paciente/cliente e despesas adequadas e justas para a instituição ${ }^{(22)}$.

Este estudo contempla o objetivo deste trabalho, trata-se de um relato de experiência sobre a implantação da auditoria concorrente em um hospital com 220 leitos. Onde é citado que, desde que o processo de auditoria concorrente foi implementado, houve diminuição dos erros de anotações de enfermagem no prontuário dos pacientes, bem como de redução do intervalo de tempo entre a alta hospitalar e o encaminhamento da fatura para o convênio. Houve também a aproximação dos enfermeiros auditores com os demais enfermeiros. Como conclusão, as pesquisadoras puderam perceber que o enfermeiro auditor deve buscar, em suas ações, o melhor desempenho possível em relação à qualidade assistencial sem tirar o foco na redução de custos. Também relatam que a auditoria realizada anteriormente era retrospectiva e que, quando houve a evolução para a auditoria concorrente, gerou-se uma melhora positiva e significativa, visto que foi possível perceber os benefícios da nova proposta ${ }^{(12)}$.

A auditoria concorrente envolve a agilidade no processo de trabalho fazendo com que não haja o acúmulo de contas e retrabalho, promovendo a diminuição de glosas e cobranças indevidas, e propiciando a descoberta de erros referentes a materiais e medicamentos no momento da própria auditoria, bem como a educação da equipe para o controle e continuidade do processo ${ }^{(23)}$.

\section{Titulo, objetivos, metodologia e principais resultados}

No quadro a seguir, serão mencionados os itens: titulo, objetivos, metodologia e principais resultados dos artigos encontrados nas bases de dados no transcorrer da revisão integrativa da literatura.

Quadro 8. Titulo, objetivos, metodologia e principais resultados dos artigos.

\begin{tabular}{|c|c|c|c|}
\hline Título & Objetivos & Metodologia & Principais resultados \\
\hline $\begin{array}{l}\text { Qualidade dos } \\
\text { cuidados de } \\
\text { enfermagem em } \\
\text { terapia } \\
\text { intensiva: } \\
\text { avaliação por } \\
\text { meio de } \\
\text { auditoria }\end{array}$ & $\begin{array}{l}\text { Avaliar a } \\
\text { qualidade dos } \\
\text { cuidados de } \\
\text { enfermagem }\end{array}$ & $\begin{array}{l}\text { Quantitativo - } \\
\text { descritivo, } \\
\text { observacional e de } \\
\text { análise documental }\end{array}$ & $\begin{array}{l}\text { - Possível avaliar a } \\
\text { qualidade dos cuidados } \\
\text { de enfermagem em UTI; } \\
\text { - Contribui para } \\
\text { direcionamento de ações } \\
\text { de melhoria da equipe }\end{array}$ \\
\hline
\end{tabular}




\begin{tabular}{|c|c|c|c|}
\hline operacional & & & investigada. \\
\hline $\begin{array}{l}\text { Auditoria de } \\
\text { enfermagem em } \\
\text { centro cirúrgico }\end{array}$ & $\begin{array}{l}\text { Relatar as } \\
\text { experiências } \\
\text { vivenciadas pelas } \\
\text { autoras durante } \\
\text { sua atuação em } \\
\text { Centro Cirúrgico }\end{array}$ & $\begin{array}{l}\text { Qualitativo - relato } \\
\text { de experiência com } \\
\text { abordagem } \\
\text { descritiva }\end{array}$ & $\begin{array}{l}\text { - Evidenciada a falta de } \\
\text { registros e de anotações } \\
\text { da equipe } \\
\text { multiprofissional; } \\
\text { - Essa deficiência } \\
\text { acarreta má qualidade } \\
\text { da assistência e } \\
\text { dificuldade na cobrança } \\
\text { dos procedimentos }\end{array}$ \\
\hline $\begin{array}{l}\text { Auditoria em } \\
\text { enfermagem: } \\
\text { identificando } \\
\text { sua concepção } \\
\text { e métodos }\end{array}$ & $\begin{array}{l}\text { Identificar e } \\
\text { analisar opiniões } \\
\text { de especialistas } \\
\text { em auditoria em } \\
\text { enfermagem e } \\
\text { sistematizar } \\
\text { tendências de } \\
\text { concepção, } \\
\text { método e } \\
\text { finalidade da } \\
\text { auditoria de } \\
\text { enfermagem na } \\
\text { atualidade e para } \\
\text { os próximos cinco } \\
\text { anos }\end{array}$ & $\begin{array}{l}\text { Quantitativo - } \\
\text { Técnica Delphi }\end{array}$ & $\begin{array}{l}\text { - Auditoria de } \\
\text { enfermagem vem sendo } \\
\text { utilizada como uma visão } \\
\text { contábil e financeira com } \\
\text { foco na auditoria } \\
\text { retrospectiva. } \\
\text { - Futuramente, a } \\
\text { qualidade da assistência } \\
\text { estará em foco, e a } \\
\text { auditoria concorrente } \\
\text { será implementada }\end{array}$ \\
\hline $\begin{array}{l}\text { Tendências da } \\
\text { função do } \\
\text { enfermeiro } \\
\text { auditor no } \\
\text { mercado em } \\
\text { saúde }\end{array}$ & $\begin{array}{l}\text { Identificar } \\
\text { tendências atuais } \\
\text { e futuras da } \\
\text { função do } \\
\text { enfermeiro } \\
\text { auditor no } \\
\text { mercado de } \\
\text { trabalho }\end{array}$ & $\begin{array}{l}\text { Quantitativo - } \\
\text { exploratório - } \\
\text { técnica Delphi }\end{array}$ & $\begin{array}{l}\text { - Auditoria está voltada } \\
\text { para a área contábil e } \\
\text { financeira. } \\
\\
\text { - Um cenário maior para } \\
\text { a auditoria concorrente } \\
\text { está sendo apresentado, } \\
\text { já que o foco será a } \\
\text { qualidade }\end{array}$ \\
\hline $\begin{array}{l}\text { Limites e } \\
\text { possibilidades } \\
\text { da auditoria em } \\
\text { enfermagem e } \\
\text { seus aspectos } \\
\text { teóricos e } \\
\text { práticos }\end{array}$ & $\begin{array}{l}\text { Analisar crítico- } \\
\text { reflexivamente a } \\
\text { auditoria de } \\
\text { enfermagem }\end{array}$ & $\begin{array}{l}\text { Qualitativo - } \\
\text { análise critico- } \\
\text { reflexiva }\end{array}$ & $\begin{array}{l}\text { - O profissional } \\
\text { enfermeiro tem que } \\
\text { garantir a qualidade da } \\
\text { assistência ao paciente } \\
\text { fazendo com que este } \\
\text { tenha confiabilidade e } \\
\text { segurança em relação a } \\
\text { esse profissional. }\end{array}$ \\
\hline $\begin{array}{l}\text { Qualidade da } \\
\text { assistência de } \\
\text { enfermagem em } \\
\text { unidade de } \\
\text { terapia intensiva } \\
\text { de um hospital }\end{array}$ & $\begin{array}{l}\text { Analisar a } \\
\text { qualidade da } \\
\text { assistência de } \\
\text { enfermagem } \\
\text { numa UTI para } \\
\text { adulto de um }\end{array}$ & $\begin{array}{l}\text { Quantitativo - } \\
\text { transversal (técnica } \\
\text { de Delphi) }\end{array}$ & $\begin{array}{l}\text { - Foi estabelecido o } \\
\text { diagnóstico situacional } \\
\text { das práticas de } \\
\text { enfermagem no cenário } \\
\text { estudado. }\end{array}$ \\
\hline
\end{tabular}




\begin{tabular}{|l|l|l|l|}
\hline escola & hospital escola & & \\
\hline $\begin{array}{l}\text { Implantação da } \\
\text { auditoria } \\
\text { concorrente de } \\
\text { enfermagem: } \\
\text { um relato de } \\
\text { experiência }\end{array}$ & $\begin{array}{l}\text { Descrever as } \\
\text { experiências de } \\
\text { enfermeiras } \\
\text { acerca da } \\
\text { implantação da } \\
\text { auditoria } \\
\text { concorrente de } \\
\text { enfermagem em } \\
\text { ambiente } \\
\text { hospitalar }\end{array}$ & $\begin{array}{l}\text { Qualitativo - relato } \\
\text { de experiência }\end{array}$ & $\begin{array}{l}\text { - A implantação da } \\
\text { auditoria concorrente de } \\
\text { enfermagem demostra a } \\
\text { relevância desta } \\
\text { metodologia de trabalho } \\
\text { aplicada ao contexto } \\
\text { hospitalar. }\end{array}$ \\
& & $\begin{array}{l}\text { - O trabalho das } \\
\text { enfermeiras, "in loco", } \\
\text { estreita as relações com } \\
\text { os demais profissionais, }\end{array}$ \\
\hline
\end{tabular}

Este estudo teve como objetivo analisar a produção científica brasileira acerca da importância da auditoria concorrente e suas implicações para melhoria assistencial e de processos nos prestadores de serviço à saúde. Foram analisados 07 artigos no total.

Os tipos de estudo em destaque foram os quantitativos de cunho descritivo, apresentando também relatos de experiências e estudos transversais. Também houve a presença de estudos de caráter qualitativo.

Como principais resultados obtidos tem-se que a auditoria concorrente ainda é uma prática pouco utilizada pela auditoria em enfermagem. Sendo assim, a auditoria em enfermagem apresenta-se ainda voltada para custos e gastos. Há uma necessidade de começar avaliações quanto à qualidade da assistência e é neste fato que a auditoria concorrente surge aglutinada à auditoria retrospectiva.

Os autores sugerem, de forma sintetizada, que os atores do processo estabeleçam canais eficientes e eficazes de comunicação e que haja uma política de continuidade do processo em todas as esferas governamentais, estabelecendo objetivos, diretrizes e, principalmente, investimentos na manutenção em equipamentos e na qualificação e atualização de todos os profissionais envolvidos.

Os estudos apontaram também a importância dos enfermeiros auditores tanto em instituições públicas quanto em instituições privadas, mas que este ainda precisa conquistar seu lugar na área se fazendo presente e não somente fiscalizando tarefas realizadas ou não.

\section{CONSIDERAÇÕES FINAIS}

O objetivo deste trabalho foi analisar a produção científica brasileira acerca da importância da auditoria concorrente e suas implicações para a melhoria assistencial e de processos nos prestadores de serviço de saúde, entre os anos de 2007 e 2017. Para tal, optou-se por realizar uma revisão integrativa da literatura. 
Durante a revisão nas bases de dados, encontramos 07 artigos referentes ao assunto, retirados de um total de 155 estudos. $O$ ano de maior publicação foi 2013 , com $28,5 \%$ das publicações. O periódico que mais continha artigos referentes ao assunto da pesquisa foi a Revista Brasileira de Enfermagem com $42,8 \%$ das publicações.

O caráter das publicações, em sua maioria, foi quantitativo de cunho exploratório, descritivo e transversal.

Com este estudo, foi possível a elaboração de duas categorias temáticas: "avaliação assistencial e redução de custos através da auditoria concorrente" e "perspectivas, limites e facilidades no processo de trabalho do enfermeiro auditor".

Identificou-se que a auditoria concorrente, quando utilizada, visa primordialmente a qualidade assistencial, principalmente em setores de gastos hospitalares maiores como Unidades de Tratamento Intensivo (UTI) e Centros Cirúrgicos. A auditoria concorrente, atualmente, é ainda pouco utilizada, visto que identificamos que a meta atual da auditoria em enfermagem segue sendo a redução de custos e contas hospitalares.

Embora seja evidente que a auditoria concorrente também contribui para esta redução de custos, é possível observar que esta avalia adequadamente a questão da qualidade da assistência ao paciente, visto que é realizada num tempo maior e "in loco", ou seja, necessita de um contato maior com paciente, familiar e equipe e não apenas por análise de prontuários. Fazendo, assim, com que o trabalho do enfermeiro auditor seja completo, dinâmico e articulador.

As mudanças nas configurações dos serviços de saúde, agora mais preocupados com qualidade e humanização, fazem com que a projeção para a auditoria concorrente seja de maior evidência. Assim, os artigos analisados preveem, para os próximos anos, que a auditoria concorrente não será um complemento e sim uma continuação da já tão utilizada, auditoria retrospectiva. Os profissionais percebem que quanto maior a qualidade na assistência menor o tempo de tratamento e consequentemente menores os custos hospitalares. Assim, a auditoria concorrente, através da avaliação da qualidade da assistência, contribui para a redução de custos hospitalares, assumindo função de grande relevância.

Em relação ao enfermeiro auditor, ainda se faz necessário que este mostre a importância e a existência do seu trabalho, trazendo para os demais setores hospitalares sua real função, de modo a articular cuidados e metas com a equipe, tanto de enfermagem quanto multidisciplinar.

A auditoria de enfermagem deve deixar de ser vista apenas como redutora de custos e investigadora de erros e passar a ser vista como um elemento que transforme positivamente as ações das equipes para com os pacientes e, por consequência, reduza custos para os prestadores de saúde.

Esta pesquisa evidenciou a escassez de estudos que relatem o uso da auditoria concorrente, mas evidenciou também que a auditoria concorrente é a aposta para o futuro da auditoria de enfermagem, visto que é um processo completo de avaliação da qualidade da assistência e posterior redução de custos hospitalares. 
Espera-se que este estudo possa contribuir para a ampliação do uso da auditoria concorrente em enfermagem, bem como para evidenciar a importância do processo de trabalho do enfermeiro auditor, trazendo para conhecimento público de que um trabalho com objetivo pautado numa investigação com propósito de melhora para os serviços de saúde e para os pacientes é de extrema relevância para a sociedade.

\section{REFERÊNCIAS}

1 Pinto, KA, Melo C MM. A prática da enfermeira em auditoria em saúde. Revista da Escola de Enfermagem USP, São Paulo. 2010; 44(3): 671-678.

2. Blank CY, Sanches EM, Leopardi MT. A prática do enfermeiro auditor hospitalar na região do Vale do Itajaí. Revista Eletrônica de Enfermagem, Goiás. 2013; 15(1): 233-242.

3. Mendes KDS, Silveira, Renata CCP, Galvão CM. Revisão integrativa: método de pesquisa para a incorporação de evidências na saúde e na enfermagem. Texto \& Contexto de Enfermagem, Florianópolis. 2008; 17(4): 758-764.

4. Ganong LH. Integrative Review of Nursing Research. Res Nursing Health, 1987. Febr; 10(1):1-11.

5. Minayo MCS. O desafio do conhecimento: pesquisa qualitativa em saúde. São Paulo: Hucitec; 2010.

6. BRASIL. Câmara dos Deputados. Lei oํ 9.610, de 19 de fevereiro de 1998. Lei dos Direitos Autorais. Disponível em:

<http://www2.camara.leg.br/legin/fed/lei/1998/lei-9610-19-fevereiro-1998-365399norma-pl.html>. Acesso em: 20 dez. 2017.

7. Mota ALC. Auditoria de enfermagem nos hospitais e operadoras de planos de saúde. São Paulo: látria; 2013.

8. Martini JG et al. Auditoria em enfermagem. São Paulo: Difusão; 2009.

9. Oliveira DR, Jacinto SM, Siqueira CL. Auditoria de enfermagem em centro cirúrgico. Revista de Administração em Saúde, São Paulo. 2013; 15(61): 151-158.

10. Setz VG, D'innocenzo M. Avaliação da qualidade dos registros de enfermagem no prontuário por meio da auditoria. Acta Paulista de Enfermagem, São Paulo. 2009; 22(3): 313-317.

11. Scarparo AF, Ferraz CA. Auditoria em enfermagem: identificando sua concepção e métodos. Revista Brasileira de Enfermagem, Brasília. 2008; 61(3): 302-305.

12. Viana CD, et al. Implantação da auditoria concorrente de enfermagem: um relato de experiência. Texto \& Contexto de Enfermagem, Florianópolis. 2016; 25(1): 1-7. 
13. Galante AC. Auditoria hospitalar do serviço de enfermagem. Goiânia: AB; 2008.

14. Padilha EF, Matsuda LM. Qualidade dos cuidados de enfermagem em terapia intensiva: avaliação por meio de auditoria operacional. Revista Brasileira de Enfermagem, Brasília. 2011; 64(4): 684-691.

15. Silva RB, et al. Qualidade da assistência de enfermagem em unidade de terapia intensiva de um hospital escola. Revista Gaúcha de Enfermagem, Porto Alegre. 2013; 34(4): 114-120.

16. Faraco MM, Albuquerque GL. Auditoria do método de assistência de enfermagem. Revista Brasileira de Enfermagem, Brasília. 2004; 57(4): 421-424.

17. Silva JA, et al. Avaliação da qualidade das anotações de enfermagem em unidade semi-intensiva. Escola Anna Nery, Rio de Janeiro. 2012; 16(3): 576-581.

18. Possari JF. Prontuário do paciente e os registros de enfermagem. São Paulo: látria; 2007.

19. Fernandes IA, et al. Análise comparativa da auditoria aplicada pela enfermagem. Revista Gestão \& Saúde, Curitiba. 2013; 8(1): 13-24.

20. Abrahão CMM. A importância da auditoria em enfermagem frente a qualidade assistencial no âmbito hospitalar público. 2013. 26f. Trabalho de Conclusão de Curso (monografia) - Curso de Enfermagem, Centro Universitário de Brasília; 2013.

21. Scarparo AF, et al. Tendências da função do enfermeiro auditor no mercado em saúde. Texto \& Contexto de Enfermagem, Florianópolis. 2010; 19(1): 85-92.

22. Siqueira PLF. Auditoria em saúde e atribuições do enfermeiro auditor. Caderno Saúde e Desenvolvimento, Roraima. 2014; 3(2): 5-19.

23. Souza MP, Ceretta LB; Soratto, MT. Auditoria concorrente no centro cirúrgico: concepções dos enfermeiros. Revista Saúde e Pesquisa, Paraná. 2016; 9(2): 263272.

Recebido: 27 junho 2017. Publicado: 14 agosto 2017

Correspondência: Ezequiel Teixeira Andreotti. E-mail: andryotti@yahoo.com.br

Conflito de interesse: os autores declaram não haver conflito de interesses 
(C) This is an Open Access article distributed under the terms of the Creative Commons Attribution License, which permits unrestricted use, distribution, and reproduction in any medium, provided the original work is properly cited 